\title{
Capacity in Maritime Archaeology: A Framework for Analysis
}

\author{
Robert MacKintosh ${ }^{1}$
}

Published online: 11 October 2019

(C) The Author(s) 2019

\begin{abstract}
Capacity development is a key tool that can be used to improve maritime archaeological research and underwater cultural heritage protection. Despite numerous capacity development initiatives there has been little written about the theoretical concept of capacity or capacity development in maritime archaeology or even archaeology more generally. This paper borrows a theoretical concept of capacity from the environmental sciences literature and demonstrates how it can be applied to maritime archaeology through the examination of the situation in three case study States: Croatia, Italy and Montenegro. It argues that all aspects of the concept of capacity need to be understood before successful capacity development initiatives can be planned, and that the development of strategies for capacity development could initiate long term positive changes in maritime archaeological capabilities.
\end{abstract}

Keywords Capacity $\cdot$ Capacity development $\cdot$ Croatia $\cdot$ Italy $\cdot$ Montenegro

\section{Capacity in Maritime Archaeology}

Capacity is a broad concept, which can be defined as "the ability of people, organisations and society as a whole to manage their affairs successfully" (OECD 2012: 27). For maritime archaeology and the protection of underwater (or maritime) cultural heritage it could be said that capacity is the ability of people, organisations and society as a whole to manage underwater cultural heritage successfully, through research, protection and promotion. Various factors interact to affect this ability. For instance, maritime archaeology is an endeavour that requires certain skills and knowledge from its participants, as well as adequate funding and access to, and an ability to use, a diverse range of equipment and technology. In addition, relevant actions are performed within certain social, legal and institutional contexts, which also influence the ability of an individual, organisation or State to effectively undertake maritime archaeology.

Capacity development is a key tool to improve maritime archaeological research and underwater cultural heritage protection. Numerous organisations, archaeologists and archaeological projects attempt to develop capacity in maritime archaeology, with some

Robert MacKintosh

r.mackintosh@wessexarch.co.uk

1 Wessex Archaeology (Scotland), 21-23 Slater's Steps, Edinburgh EH8 8PB, UK 
of the activity in recent years being linked to the UNESCO 2001 Convention on the Protection of the Underwater Cultural Heritage, either directly through the work of its secretariat, or undertaken in its name by other parties (UNESCO 2017; Favis et al. 2012). These efforts usually focus on training actors in various aspects of maritime archaeology or underwater heritage management (Anderson 2014; Manders and Underwood 2015). Success is often measured by listing the numbers of actors trained, or the number of courses run (Manders and Underwood 2015: 748).

But do these capacity development efforts succeed in raising capacity? On the face of it, it would seem that increasing the number of people that are trained and educated in maritime archaeology must improve capacity. But what if these newly trained people then remain inactive as there are no relevant jobs in their States and no institutions that can continue to support them? What if they have no access to boats, diving equipment, or remote survey equipment, no funding to undertake projects, or no avenue to disseminate their results? Does merely counting the number of participants in a course give a true indication of whether capacities have been increased?

There is a problem here that partly stems from the lack of discussion about what exactly capacity means, and what the aims of capacity development efforts are. Despite attempts to increase capacity, there is a paucity of literature in maritime archaeology or even archaeology more generally, about the concept of capacity, or the process of capacity development. However, other disciplines such as the environmental sciences and natural heritage protection have a firmer theoretical footing than archaeology in this regard, as capacity and capacity development have been sources of discussion in these fields for quite some time, particularly since the UN Conference on Environment and Development in 1992, also known as the Earth Summit, which focussed on sustainable development, and the international cooperation needed to raise capacities to meet its environmental and developmental aims (UN Conference on Environment and Development 1992). Archaeology and the environmental sciences have much in common, indeed they are both underpinned by scientific methodologies, and are both concerned with the protection of the object of their study, which could be called heritage, cultural and natural. Maritime archaeologists working in cultural heritage protection could learn a number of lessons from the better funded and perhaps more established literature relating to natural heritage protection, particularly where it relates to policy and governance.

This article therefore explores a theoretical concept of capacity, borrowed from the environmental policy literature, and demonstrates how it applies to a maritime archaeological context. Capacity is a concept with different facets, it does not just encompass the skills of individuals, and these different facets will be examined through the description of the situation in three case study States: Croatia, Italy and Montenegro. It will be argued that in order to design successful interventions, i.e. for capacity development efforts to have a positive effect, certain aspects of capacity, particularly 'framework conditions', or pre-existing background systems, have to be taken into account. Capacity development initiatives could have lasting impacts on capacity by developing strategies that account for these conditions, and tailor their measures accordingly.

We urgently need an understanding of capacity in maritime archaeology that goes beyond the abilities of individuals, so that we can better focus our limited time and resources, and plan more effective interventions. It is hoped that the conceptual framework presented in this article will assist archaeologists as they plan, undertake, and measure the impact of their capacity development efforts. 


\section{The Concept of Capacity}

There are numerous models of capacity laid out in the environmental policy literature, but one that provides a useful framework for analysis for maritime archaeology has been by produced by Jänicke (1997). This framework suggests that perceived problems lead actors to develop solutions under systemic conditions and within situative contexts (Jänicke 1997: 4). The ability to solve these problems, i.e. capacity, is therefore influenced mainly by the following factors:
(a) structure of the problems,
(b) actors,
(c) systemic framework conditions,
(d) situative contexts,
(e) strategies.

Firstly, the ability to solve a problem depends on the nature of the problem itself (Jänicke 1997: 8). Whether it is easy or hard to solve, whether it is experienced by the public, or whether it is urgent or latent, can all affect the capacity to solve it. There are certain challenges inherent to maritime archaeology and underwater heritage protection that will be familiar to practitioners the world over. They provide fixed conditions that affect the maritime archaeological capacity of States. Perhaps fundamentally, underwater cultural heritage is remote and difficult to access, which causes problems for its protection. In many cases only limited investigation of the seabed of a State's waters will have been undertaken, and limited discoveries of underwater cultural heritage made. Merely knowing that destruction of underwater heritage has occurred is often difficult. Another consequence of its remote location is that underwater cultural heritage is often unseen by the public, so its fate is often of no immediate or known consequence to the public, and therefore also to politicians. Underwater archaeology is often therefore less well funded than terrestrial archaeology and its economic benefits are less immediately obvious (Firth 2015). Compared to other traditional aspects of a Ministry of Culture's budget such as museums, or especially to other governmental areas, such as defence, finance, or even the environment, underwater archaeology is often of a much lower priority. The inherent characteristics of underwater and maritime archaeology cannot easily be changed, but capabilities relating to the other aspects of the concept of capacity may be developed to alleviate these problems.

The concept of actors is perhaps the most familiar to maritime archaeologists. This is often termed individual capacity (OECD 2012: 28), and focuses on the competencies of the individual, such as knowledge, skills and abilities (Jänicke 1997: 6). It is an important aspect of capacity, and building human resources is essential in capacity development efforts, but it is not sufficient on its own. The United Nations Development Programme (UNDP) for instance states that their approach to capacity development "looks beyond individual skills and a focus on training to address broader questions of institutional change, leadership, empowerment and public participation" (United Nations Development Programme 2008: 3). However, this is the aspect of capacity that has been the focus of most capacity development efforts in maritime archaeology thus far, i.e. training individuals in order to improve their knowledge and skills (UNESCO 2017). Actors are vital in in the maritime archaeological capacity of a State, however, training alone is not sufficient to build capacity, those that are trained require more than knowledge to be effective. The abilities of the individual are always limited by certain external conditions. 
The systemic framework conditions are the "systemic conditions of... action or the opportunity structure of the relevant actors" (Jänicke 1997: 6). These include three distinct but interrelated and interacting groups of framework conditions. The first of these are the cognitive-informational framework conditions. These are the conditions under which knowledge is "produced, distributed, interpreted and applied. Without knowledge there is no (perceived) problem, no public awareness and consequently no policy process" (Jänicke 1997: 7). When the cognitive-informed framework conditions are applied to maritime archaeology, three levels are identified, the ability of archaeologists to produce information, the dissemination of this information causing or raising public awareness, and hopefully, consequent political awareness. The second, political-institutional framework conditions, are the constitutional, institutional and legal structures constituting the framework for interaction (Jänicke 1997: 7). Finally, the economic-technological framework conditions are perhaps the most obvious, and include, amongst other things, the gross domestic product (GDP) of a State, and the availability of technology (Jänicke 1997: 7). These framework conditions affect and limit the capacity of a State, so that capacity development initiatives that do not seek to understand and alter them may only achieve partial or temporary success.

It is important to remember that none of these framework conditions are static. They are subject to short term variable conditions, known as situative contexts (Jänicke 1997: 7). These are often events that spark public debate, such as the Chernobyl, Bhopal or Seveso disasters and the opportunities these offered for proponents of environmental protection. In the case of maritime archaeology, discoveries or destruction of famous shipwrecks may have an analogous effect, but the situative contexts may be much smaller scale and more mundane also, such as an actor changing jobs, or funding for a particular project running out.

Finally, a strategy is "the general approach to the problem. Strategy is the purposeful use of instruments, capacities, and situative opportunities to achieve long-term goals" (Jänicke 1997: 6).

When considering this conceptual framework, it is immediately obvious that the concept of capacity is multifaceted and complex. Examining the archaeological capacity of, for example, a particular State, is difficult as the interplay of its context and framework conditions will be unique and will not be static (Browne 2002: 3). In addition, the framework shows that there are certain limits to attempted capacity development interventions and those that merely train actors without taking into account the underlying frameworks and contexts will only have superficial success. Failure of capacity development efforts cannot just be explained by 'intervention failure', the structural conditions also matter (Jänicke 1997: 3).

The concept of capacity, thus far presented, is abstract and would benefit from further elucidation. The individual skills and knowledge of actors and the inherent characteristics of maritime archaeology are well understood and do not require further detailed discussion. However, the systemic framework conditions, situative contexts and strategy aspects of the concept will be demonstrated with reference to maritime archaeology in more detail by applying them to three case studies, focussing on Croatia, Italy and Montenegro.

\section{Data Collection}

This article was born out of wider doctoral research investigating the effects of the 2001 UNESCO Convention on the Protection of the Underwater Cultural Heritage in 
its States Parties, and the reasons behind the varying levels of its implementation and effectiveness (MacKintosh 2018). For that research five States which displayed different levels of implementation and influence of the 2001 Convention, all located around the Adriatic, were chosen for further study. For this article, only three of the States have been used, Croatia, Italy and Montenegro, as these give a sufficient range of experiences to adequately demonstrate the concept of capacity and to explore the application of the analytical framework in the context of maritime archaeology. Two of these countries, Italy and Croatia, have long histories of maritime archaeology. In Montenegro maritime archaeology is relatively nascent, and could be perceived, at first glance, as less developed than in Italy and Croatia. All three of these States have ratified the 2001 UNESCO Convention, most recently Italy in 2010. Croatia became one of the Convention's early adopters in 2004.

Data for these case studies is drawn from a series of interviews that were undertaken in 2016 as part of the wider doctoral research. Qualitative interviews were chosen as the research method as the relevant data relating to the non-legislative effects of the 2001 UNESCO Convention, and factors that influenced its implementation, were not available in any other form (Mason 2002: 66). Data collection took place in summer 2016 and consisted of 15 semi-structured interviews with 16 archaeologists, government officials and legal academics in the three States. The interview participants were purposively chosen as they were either directly involved in the implementation of the 2001 UNESCO Convention, or worked within the legal, institutional and cultural frameworks that could be expected to affect the implementation of the Convention, and so were able to provide data that could be used to answer the research questions. The sample size is relatively limited, and skewed towards Croatia and Italy, but this is due to both the availability, and even existence, of relevant participants in the target countries and also the time and resources available to the author. Conclusions will therefore be accordingly constrained.

This article is meant as an exploration of the conceptual framework of capacity in a maritime archaeological context. It will illustrate the aspects of this framework through description of cases using the opinions of actors with authority as evidence (Mason 2002: 176). The data will therefore consist of the participants' experiences and perceptions of the archaeological and heritage management systems in their States. The relevant interviews will be cited when presenting these data using the designations I1-I8 for Italy, C1-C5 for Croatia, and M1 and M2 for Montenegro.

A further point needs to be expressed at this stage. In the environmental literature there is much debate about a North versus South divide, or a divide between developed and developing countries (Sagar 2000; Sagar and VanDeveer 2005: 17-19). The flow of capacity development usually goes one way, from North to South, from developed to developing, despite the systems in place in the developed countries never being perfect, and often causing some of the problems for other States in the first place. Consider the exploitation of the underwater cultural heritage of developing States by nationals and companies of the US, UK and other Western European States through treasure hunting and salvage. The State the author works in, primarily Scotland, has its own deep-seated problems with maritime archaeological capacity, whereas two States in this article, Italy and Croatia, have long histories of maritime archaeology and can themselves be considered leaders in the field. This is something the author has been very aware of whilst conducting this research, and it is not their intention to be overly critical of the systems of other States, or the efforts of those working in the discipline, or to imply that the situation in Scotland is any better. However, an honest and open debate about the situation in many States needs to be conducted, otherwise capacity development efforts will be slow or ineffectual. 


\section{The Capacity Framework Applied to Maritime Archaeology}

Particular unfamiliar aspects of the concept of capacity, the systemic framework conditions, situative contexts and strategy, will now be explored from the perspective of maritime archaeology and applied to the situation in the three case study States.

\section{Systemic Framework Conditions}

The systemic framework conditions, forming the opportunity structure of the relevant actors, are fundamental to the capacity of a country, and provide limits on the success of capacity development efforts. They can be divided into cognitive-informational, political-institutional, and economic-technological framework conditions. All three types of framework condition will be explored in each State in turn, to show how their complex interaction has affected capacity in each State.

Italy Italy has a long and varied history of maritime archaeology. As long ago as the fifteenth century people were investigating two submerged Roman vessels in Lake Nemi (Ucelli 1950), and as early as the 1950s such underwater investigation began to be placed on a more scientific footing, with excavations of wrecks at Albenga and Spargi notable in this regard, with archaeologists such as Nino Lamboglia leading the way (Throckmorton 1996: 64-65).

Recently however, it has been said that there is a crisis in underwater archaeology in Italy (I4; Secci and Stefanile 2016). Many of the problems of capacity within the Italian State seem to stem from its political-institutional framework. As all archaeology in Italy is regulated by the Cultural Heritage and Landscape Code (Decreto Legislativo 42/2004), underwater cultural heritage management, despite its different challenges and specific issues, is subsumed within the general legal and institutional structures in Italy. These institutions include the Ministry of Cultural Heritage, Activities and Tourism (since renamed the Ministry of Cultural Heritage and Activities) at the centre, and its regional Soprintendenze (Superintendencies) which are responsible for both protection and research in their territories. In 2016 there was a different system in Sicily, which had its own Soprintendenza del Mare (Superintendency of the Sea), which was unconnected to the central Ministry.

These disparate regional institutions rarely employ actors familiar with underwater archaeology (I3, I4, I6, I8). To become a public servant in Italy you have to wait for an open competition. The last such competition for underwater archaeologists was held in the mid-1980s. That means there has been no addition of maritime archaeologists to the central ministry, or the regional Soprintendenze since 1986. There have been other general calls for archaeologists, including one in the summer of 2016, but the selection of candidates is down to the quality of the candidates themselves and not their subject interest (I6). The ability of a region therefore to research underwater archaeology, and proficiently assess permit and development applications, relies on the chance that someone with a maritime archaeological background is successful in the competition and assigned to the region. In addition, those that retire or move on are not replaced until the next competition. The generation that was employed in the 1980s are all now retiring, leaving a knowledge vacuum which is being filled temporarily by re-employing some of them on a consultancy basis (I1). This cannot be a long-term solution. So underwater 
archaeology in Italy depends on the skills and interests of individuals, not on any uniformity in institutional practice. As one participant stated: "This is not normal in an advanced country" (I6).

Further, authority over the protection and promotion of cultural heritage was separated in a constitutional amendment in 2001 [Constitution of the Italian Republic, as amended, arts 117(2)(s) and (3)]. The State now has exclusive legislative authority over the protection of cultural heritage, and the State and Regions have concurrent legislative authority over the enhancement of cultural and environmental heritage, including their promotion and the organisation of cultural activities (Secci and Stefanile 2016: 101). This means that power was devolved to the Italian regional governments over promotion activities, which includes public outreach and public access, amongst others. Whilst this is arguably beneficial, as different regions have different cultures and different site types, and local knowledge is therefore required to understand and promote the heritage effectively, there is no set national standard for these enhancement activities, they depend on the whims of the regional governments (I3).

This fragmentation of powers and geographical unevenness of expertise affects the capacity of the State, and the ability of individual actors to effectively practice maritime archaeology. This problem of geographical unevenness, particularly in the Soprintendenze, has been identified by others:

Such [regional] differences often derive from different sensibilities among appointed territorial officers, creating once again, a heterogeneous approach possibly ascribable to a limited central coordination, posing limits to the full and unvarying development of the discipline on the whole country (Secci and Stefanile 2016: 102).

The limited central coordination was identified as a major factor affecting Italy's capacity by the interviewees (I3; I4). One participant stated:

...there is a lack of interest in the Ministry of Culture, which I am not able to explain. Of course lack of a special Soprintendenze, of a special unit working only on underwater archaeology can be one of the causes, as there are no archaeologists in the Ministry of Culture which are specialist and so which are responsible for what is happening. So there is a sort of simple ignorance of the problem. We can say the situation was very different fifteen years ago. Because there was a debate on the programme of underwater cultural heritage. This debate is dead. And the causes are not so clear... So mainly the problem is the lack of special offices, special archaeologists working on it. It was all left to the initiative of a single archaeologist of the Soprintendenze. And this doesn't work because now this lack of specialists has caused this empty space, lack of attention on the problem (I4).

This may all stem from underwater cultural heritage management being subsumed within the general legal and institutional structures of cultural heritage management (I3). Heritage managers take decisions according to their own initiative, and according to the very general Cultural Heritage and Landscape Code, rather than some set of common standards or policy for underwater archaeology (I3).

Therefore, the primary systemic framework condition that is causing problems with capacity in Italy can be said to be political-institutional, relating to the administrative processes by which archaeologists are employed by the State, the regional structures of the State institutions, and the legislative framework that separates the authority for the protection and enhancement of cultural heritage, and which subsumes the protection of underwater cultural heritage within the general systems of heritage protection. 
It has been suggested that a national Soprintendenza Del Mare, built along the same lines as Sicily's Soprintendenza Del Mare, would alleviate some of these issues and build cohesion in the way that underwater cultural heritage is protected and underwater archaeology is practiced in Italy (Secci and Stefanile 2016: 102). Such an idea has been considered since the 1990s, and recently has twice found its way to being presented to the Italian parliament (Stefanile 2014). In 2009, a bill was submitted which provided for the establishment of a national Soprintendenza del Mare, with central offices in Rome and regional offices for the Tyrrhenian and Adriatic Sea at Orbetello and Venice (Proposta di legge 2302/2009). In 2013 another bill was submitted which proposed the creation of a central Centre for Underwater Archaeology, four regional Soprintendenze for underwater archaeology in Venice, Rome, Genova and Cagliari, and Cape Rizzuto Island, as well as three conservation laboratories and 11 museums of underwater archaeology (Proposta di legge 470/2013). Both bills failed for what seem to be reasons purely to do with the political process in Italy. The Ministry of Cultural Heritage has been going through recent reforms, which notably separate museums from the Soprintendenze, and merge the responsibilities for archaeology with those over fine art and the landscape. The 17 archaeological Soprintendenze are being incorporated into 39 unified offices with responsibilities for archaeology, fine arts and landscape (Decreto 208/2016). The idea of a central institution for underwater archaeology has not been revived, and interview participants have noted their concern that underwater archaeology has not even been mentioned in the recent far reaching reforms (I1; I6; Secci and Stefanile 2016: 102-103). This may exacerbate the existing problems, as now there are 39 regional offices that would ideally need to employ an underwater archaeologist, rather than 17.

So why is it said that there is a crisis in maritime archaeology in Italy? The framework for analysis shows us that capacity, the ability of archaeologists to adequately practice archaeology, is limited by certain framework conditions, particularly-political institutional conditions. To build capacity in Italy, these framework conditions must be addressed, and the institutional system reformed, as without this, no matter how skilled the individual archaeologists, research and protection will remain uneven and reliant on chance.

Croatia Croatia also has a long history of maritime archaeology (Rossi 2012). As a constituent republic of Yugoslavia the protection of underwater cultural heritage was ensured by Yugoslavian law, but unlike in, for instance, Montenegro and Slovenia, most of the infrastructure, archaeologists and thus research that took place in Yugoslavia, was located in the Croatian territory. The development process in Croatia was by no means linear however, and some important institutional features were subsequently lost in Croatia (Rossi 2012: 293). Nevertheless, today the country is among the world leaders in maritime archaeology, with a very high number of projects undertaken and maritime archaeologists in employment.

The abilities of its actors are hindered, on the face of it, primarily by economic- technological framework conditions, however the cognitive-informational and political-institutional framework conditions also play their part. The Ministry of Culture have explained that the country has been affected by the financial crisis of 2007-2008, and this triggered austerity measures which heavily affected the Ministry of Culture (Florea and Gheorghiu 2015: 13; Ratzenböck et al. 2012: 22).

Due to this, the International Centre for Underwater Archaeology (ICUA) in Zadar, established in 2007, which became a UNESCO Category 2 Centre in 2009 with a remit of promoting underwater archaeology in the region, fostering cooperation, and education, and also conservation and research duties, has been consistently 'understaffed and 
underfinanced' (Florea and Gheorghiu 2015: 3). The agreement between UNESCO and Croatia specified that the Ministry of Culture was to provide annually a minimum amount of $\$ 918,000$ to ICUA (Agreement between UNESCO and the Government of the Republic of Croatia 2008: art 13). This figure, between 2008 and 2014, was not met (Table 1).

ICUA has a dual nature, as it was originally conceived of as a national centre but then subsequently was given an international remit. This has caused it problems, such as having an expectation to undertake projects in other countries but without the funding to deliver them (C2). The UNESCO funding received by ICUA is only for particular projects or courses, in order that they include people from other States, especially in South Eastern Europe (C2). Understandably perhaps, Croatia has been unwilling to fund projects in other States, and those other States are also reluctant to fund ICUA to help. International meetings are often held where interest is expressed in collaboration in the protection of underwater cultural heritage and developing capacities, but even when followed up by staff from ICUA, few practical results ensue.

ICUA is also understaffed. It has five permanent staff members, and only one is a permanent underwater archaeologist, with around five more employed on a temporary, project basis (C2). This number must be compared to the 20 or so that were originally envisaged. This means that employees take on dual roles, including the director having to dive and work as an archaeologist. There is also a high turnover of temporary staff, which means that a larger number of people can gain basic underwater archaeology skills, but also means that just as staff are becoming useful to the centre (in that they become more experienced at diving and practical underwater archaeology, and therefore need less supervision), they have to leave as their project ends and there is no other position or money to retain them. ICUA then has a gap of six or 12 months before this staff member is replaced and the training has to start again from the beginning. If the Centre is meant to help foster archaeology in other States, constantly having novices on staff that cannot help or teach others, is a drawback.

ICUA has been doing excellent work with the resources it has been given, it trained 112 people in various courses between 2011 and 2014. Again however, this seems to be due to archaeologists working extremely hard in very difficult conditions. There were high expectations for the centre, but it may be unfair to judge the work of the centre against these, as it has not received the amount of funding or support that it was promised. The capacity of the ICUA is thus limited by these factors.

The problem is compounded by Croatia's institutional framework. There is also a Department for Underwater Archaeology in the Croatian Conservation Institute (CCI) in Zagreb, and while it mainly carries out rescue and research of endangered underwater cultural heritage (C4), their duties are similar to ICUA. The CCI are also hampered by ICUA's dual nature. When ICUA was first conceived as a national centre it was intended that the CCI would undertake all archaeological research, and all the conservation,

Table 1 ICUA: total budget 2008-2014 (in US \$, approximate figures) Source: Florea and Gheorghiu (2015: 12)

\begin{tabular}{lllllllll}
\hline Source & 2008 & 2009 & 2010 & \multicolumn{1}{l}{2011} & \multicolumn{1}{l}{2012} & 2013 & 2014 & Total \\
\hline State budget & 0 & 19,564 & 15,427 & 110,714 & 141,143 & 199,448 & 306,367 & 792,663 \\
UNESCO & 0 & 0 & 0 & 7469 & 8742 & 22,888 & 47,616 & 182,756 \\
Other sources & 0 & 49,760 & 0 & 39,307 & 31,120 & 16,551 & 46,018 & 86,715 \\
Total & 0 & 69,324 & 15,427 & 157,489 & 181,006 & 238,887 & 400,001 & $1,062,134$ \\
\hline
\end{tabular}


exhibition, publication and training work would take place at ICUA (C1; C2; C4). When ICUA became a UNESCO centre however, it could no longer be a governmental body, and so separated from the CCI, which thus lost all its conservation facilities.

Both institutions compete for the same funding from the Ministry of Culture. This is in addition to museums that employ maritime archaeologists, and also academic maritime archaeologists, most notably at the University of Zadar (C2). All the maritime archaeologists in Croatia therefore are in effect competing for funding. Lots of people apply to the Ministry each year for this funding, and everyone gets only a small amount (C4). The Ministry attempts to satisfy everyone (C1). This was described as 'Solomon's solution', a reference to Solomon's judgement where he proposed cutting a baby in half, as nobody gets quite enough money to do anything properly (C4).

This is compounded by there being no overarching State plan or research framework. This leads to sporadic, year by year funding (C4), meaning that some projects are left half finished, and sites left open for looters. If a larger sum was given in the first place, a site could be investigated properly and published (and then reburied and protected), rather than having a little money each year and having to return again and again, which ends up adding costs and taking more time.

Frustration was also expressed in relation to administrative issues (C2; C4). In particular, contracts from the government will typically be issued in June, then permits have to be sought so that work can only really start in August, with the timing and likelihood of the project remaining uncertain before that. This impacts on international cooperation particularly, as set dates for projects can never be given until relatively late on $(\mathrm{C} 2)$.

This all comes down to a lack of planning and also a lack of understanding of the logistics and needs of underwater archaeology from the Ministry, so that financially, regarding staffing, and administratively the practice of underwater archaeology in Croatia is struggling.

Further, underwater archaeology, especially when it involves diving, can be a dangerous and exhausting job, with long periods of time spent away from home. It takes time and money to ensure that staff are adequately trained and experienced, and that equipment is maintained, so that diving can be undertaken safely (C2). This led one participant to remark that politicians did not realise the work that goes into maritime archaeology, but also that they did not care (C4). Jasen Mesic, an underwater archaeologist that became Minister of Culture for a short period, drove the underwater archaeology cause whilst he was Minister. During this period the problems were understood, but following his tenure, the understanding has seemed to have disappeared again (C4).

In Croatia economic factors are blamed for problems by the Ministry of Culture (Florea and Gheorghiu 2015: 13), suggesting that economic-technological framework conditions are limiting the capacity of the State. However, on closer examination these economic factors are exacerbated by the institutional and administrative structures, particularly the duplication of institutional remits, and a lack of understanding of the practical needs and logistics of maritime and underwater archaeology by certain institutions and individuals. This would suggest that the political-institutional and cognitiveinformational framework conditions are also impacting on the capacity of the State and, in contrast to Italy where there is one type of systemic framework condition primarily affecting capacity, the efforts of the highly skilled actors in Croatia are limited by all three types of systemic framework conditions, demonstrating that a multifaceted theory of capacity is needed to adequately explain the situation in Croatia. 
Montenegro In contrast to Italy and Croatia, Montenegro has a shorter history of maritime archaeology, and so the most influential type of framework condition there is arguably cognitive-informational. There is very little understanding of what maritime archaeology is and the need for underwater cultural heritage protection (M1). Despite having ratified the 2001 UNESCO Convention, there is little awareness that in the Ministry of Culture that it even exists, and there is even still confusion over which body is responsible for ensuring the implementation of the Convention. Little consideration may have been taken of the obligations of the treaty at the time of ratification, as Montenegro ratified all UNESCO's cultural conventions, as well as numerous other treaties, shortly after gaining independence in 2006 (M1).

As in the other two States, in Montenegro the cognitive-informational framework conditions interact with the other framework conditions. For instance, there is a lack of a dedicated underwater archaeology institution in Montenegro. When the Institute for the Protection of Cultural Monuments was reformed in 2011, it was initially planned for the new Centre for Conservation and Archaeology to have a department for underwater archaeology, however, this never materialised. Instead three archaeologists were trained to dive and were supplied with diving equipment (M1). This training was provided by a diving centre in Bijela which specialises in clearing unexploded ordinance and has no archaeologists on staff (M2). The course therefore focussed on teaching diving and some survey and excavation methods, rather than on underwater archaeology. Some underwater archaeological projects do get undertaken in Montenegro as a result, which amount to around 10 days of diving a year, but this depends on the initiative of the individuals.

So there are some skilled and knowledgeable actors in Montenegro, but they are working in an institutional vacuum. There is no official at the Ministry of Culture with responsibility for underwater archaeology. One employee, who happens to have studied underwater archaeology, is the only actor in the institution familiar with the subject, and so all issues related to underwater archaeology pass through their hands (M1). One participant constantly said that they have "skipped the first steps" of creating a functional system for the research and protection of underwater cultural heritage (M1). Having trained a small number of actors in underwater archaeology, there is some capacity to research underwater cultural heritage, but there is no framework for protection, either legal or institutional. One fifteenth-century wreck located in the Bay of Kotor has achieved legal protection, but no further steps have been taken, and it is thought that it is still being looted, with no way to monitor the site or enforce the protection (M1). Looting can be reported to the inspectorate, but those actors have little understanding of the protection of underwater cultural heritage, and no concept of what practical measures they should take to rectify the situation.

There is apparently enough money to set up an institution to research and protect underwater cultural heritage, if the political will were there also (M1). It would seem therefore, that Montenegro's capacity in maritime archaeology is not primarily limited by economic-technological framework conditions, but rather through a general lack of knowledge of maritime archaeology in Montenegro and its governmental organisations, which is exacerbated by the lack of an institution dedicated to maritime archaeology, and a legal framework for its protection. 


\section{Situative Contexts}

The picture given above of the systemic framework conditions present in each State is a snapshot of the situation as it was in Summer 2016. However, none of these framework conditions are static. Indeed, the situation in Croatia at the time of writing in 2019 has changed drastically since the data collection for this article took place in 2016. In particular ICUA has added more permanent employees to its staff, including another permanent archaeologist, and it now receives around $\$ 500,000$ annually from the Ministry of Culture, as well as funding for the organisation of courses and field schools outwith Croatia, including in Slovakia and the Czech Republic (Pešić, pers. comm.). Actors in Croatia are also very aware of the situation they work in, and although institutional structures are often difficult to change, they are currently working with the Ministry of Culture to establish a system that engenders cooperation, rather than competition, between the institutions working in underwater archaeology in Croatia. These changes in Croatia seem well founded, brought about through positive decisions of the Ministry of Culture, and are likely to increase the capacity of Croatia in the long term. Changes in capacity however, can also be driven by short term variable conditions, known as situative contexts.

An example of a situative context from Italy was particularly illustrative and will suffice to demonstrate the concept. In Venice there was period of intensive underwater archaeological activity related to the construction of a system to protect Venice from flooding, known as the Mose system. The project provided a lot of money and opportunity to undertake underwater archaeology in the Venetian Lagoon. At this time there was also an archaeologist that was specialised in underwater archaeology employed by the regional Soprintendenza. The conditions therefore were, for a short time, very conducive to underwater archaeological research, so much so that it "seemed that underwater archaeology was all and land archaeology was secondary archaeology" (I4). However, the project was subject to a scandal: in 2014, 35 people including the Mayor of Venice were arrested on corruption charges related to the project (Yardley and Pianigiani 2014). Therefore, the building of the Mose, and the money related to it, stopped. Around the same time, the underwater archaeologist in the local Soprintendenza moved to a different Soprintendenza. One participant explained the effects of these situative contexts on capacity adeptly and the quote is worth setting out here at length:

Because of these two elements from the day to the night, underwater archaeology had a collapse, and now we have no works, no attention, to what is happening underwater. So it seems that underwater archaeology in the Lagoon, in the sea of Venice, does not exist. So the question is did you joke me some years ago, telling me that there was archaeology everywhere? Or are you closing the eyes now? Because its absent. So I think its a particular situation of Venice. But in general, the management of cultural heritage, especially underwater archaeology, in Italy is related to some factors, temporary factors, which are the interest of one archaeologist to the topic. So if he moves, and it arrives, an archaeologist, a prehistorian, then underwater archaeology closes. This is the same problem in other archaeology. And a problem of the management of archaeology in Italy.

The second aspect is the money. If you have no money, ordinary funds for this problem, and you leave taking money from the private companies, it is normal that when the private companies stop, if big buildings stops or closes, you have no funds and you cannot do anything in archaeology. So you cannot manage, control the territory, 
because you have not got regular funds. You have not got the structure with the specialist. You live according to the day, the weather. Its absurd. So I think underwater archaeology in Italy should have a permanent structure, permanent funds to this subject, or else it will always be in the history of peaks and troughs. It has no sense. It is not serious. So we should think in a completely new way... You need a special Soprintendenza with archaeologists working underwater with technicians, divers, and a laboratory for conservation. If you have not got this kind of structure, and special funds to do, you will live always according to various factors happening, crises, availability of money, interest of the single... Its not a wonderful panorama, but this is the reality in Italy (I4).

This demonstrates that maritime archaeological capacity is often subject to short term factors that are out of the control of archaeologists and heritage managers. These situative contexts are perhaps particularly damaging when acting in a context where certain systemic framework conditions are present, for instance in Italy, the lack of a dedicated maritime archaeological institution, the lack of a planned approach to the employment of maritime archaeologists within the Soprintendenze, and the lack of consistent funding, all mean that maritime archaeological capacity is particularly susceptible to short term external variables.

\section{Strategy}

When considering the situative contexts and the systemic framework conditions in all of the case study States, a recurrent phenomenon can be discerned. This is the absence of a fundamental aspect of the capacity conceptual framework, that of the strategy. Strategy is a relatively unambiguous concept, it is the general, planned approach to a problem (Jänicke 1997: 6). A common theme brought up by the interview participants in each State was the lack of a strategy or programmatic approach to underwater cultural heritage management, the reactive nature of heritage protection and research, and the constant reliance on the personal initiative of individual maritime archaeologists (C1; C4; I3; I4; I6; M1).

One participant in Croatia identified this lack of strategy as the root problem affecting their capacity: "the main problem here is no centralised or national plan", and later: "there is no plan. No one thinks a few steps ahead" (C4). All other issues stem from this. The lack of a central controlling institution means all other institutions compete. It means that particular archaeological sites or discoveries are not prioritised for funding, meaning all projects get less funding than they need. It leads to sporadic funding, leading to excavations being half finished, and sites being left open for looters. It means that ICUA was created as part of the CCI, and then made a UNESCO centre which removed all the conservation facilities from the CCI. It means that no future improvement is envisaged, there is no forum in which to identify problems with capacity, and no proposals developed to rectify them.

For Italy, it was also cited as "the main issue":

I think specific rules and generic rules that can be applied with just a little intervention of the individual I think will give more coherence to the overall system, and not so many different approaches from, I don't know, south, north, east, west, etc. And it's not the fault of the individuals obviously, it's a matter of being programmatic. Of being systematic and programmatic... So systematic rules that you can apply because otherwise it's like a wild west where everyone is aiming to the best but does 
so many different things that especially when you want to have a career in an osmotic environment, it just starts to crash. That's the, I think, the main issue (I3).

The regional unevenness of protection and research in Italy is exacerbated because there is no central strategy (I3; I4; I6; I7). There is no central guidance on the priorities of protection and research, and research is driven largely reactively by the necessities of rescue excavations, so no informed choices can be made about what to concentrate time and resources on (I4). There are no guidelines given by the Ministry about what level of protection underwater cultural heritage needs and the practical measures that can be taken to meet these standards (I6). Production of such guidelines would go some way to alleviating the problem of institutional memory when an underwater archaeologist leaves a region. Where there is no underwater archaeologist employed in the region it would give very basic processes and requirements, such as note that an underwater archaeologist is required to undertake interventions on underwater cultural heritage and assess the impacts of developments. There is little communication and coordination between the central Ministry and its Soprintendenze. If underwater archaeology is neglected due to the choice or interests of an individual actor, the Ministry does not question this or attempt to ensure underwater archaeology is not ignored (I7). "But what it feels, most of the time, and I mean in my opinion, but I think lots of my colleagues will agree, is that you are left alone. You know?" (I3).

In Montenegro this lack of strategy has led to "skipping steps" (M1), with research being attempted without the necessary institutional and legal frameworks in which to situate it. There is little forethought about the benefits that maritime and underwater archaeology, and even terrestrial archaeology, could bring in the long term, and thus the lack of the proper research and protection of heritage (M1).

While the framework conditions and situative contexts in each case study are complex and ever changing, this one common thread ran through them; there is always a lack of a considered approach to underwater archaeology. Underwater archaeology remains reactive, with sporadic funding, ill-conceived institutions, and regional variations. The strategy aspect of the capacity concept could be the variable common to all case studies and allows the systems in each State to retain deep rooted problems, which largely remain unexamined and unspoken.

\section{How to Improve Capacity in Maritime Archaeology}

It has been claimed that successful environmental protection "is brought about by a complex interaction of influences and not by a single, isolated factor, nor a favourite instrument, nor a single type of actor, nor a particular framework condition or institution" (Jänicke 1997: 4). 'Mono-factorial' approaches to capacity development that see single policy instruments or interventions attempt to alter the structural framework conditions in a top down manner are decried in the literature (Jänicke 1997: 4). Training individuals is an example of a mono-factorial approach. An understanding of the complex interactions between systemic framework conditions and situative contexts is perhaps more important than the type of measure introduced to alter them.

The examination of capacity in the case study States has made clear that this conceptual framework can also be applied to maritime archaeology and underwater cultural heritage protection. The issues with capacity identified by the interview participants are well explained when the framework for analysis suggested by Jänicke is applied to them. The situation in each State was complex and a State's capacity was affected by 
an intricate interaction of framework conditions and short-term variables. Therefore, capacity development measures that ignore these framework conditions and contexts, and adopt a mono-factorial approach, are as likely destined to irrelevance when applied to maritime archaeology as they are when applied in the environmental sciences. Engagement with the other aspects of the theoretical concept of capacity, beyond the skills and knowledge of individuals, is essential to successful capacity development in maritime archaeology.

A focus on the concept of strategy may prove to be the best use of time and resources in capacity development initiatives in maritime archaeology. In all three cases examined creating a strategy for improvement tailored to the particular context, which includes a close examination of the framework conditions and contexts, made by those that best understand these conditions in the State (ideally people who work there), where feasible, would be of great use. They need sub-goals, ways to measure progress and reflexively alter strategies, and need at all points to strive for the purposive improvement of capacities. This could be led by the States themselves, or by archaeologists working in those States.

These strategies could be blueprints for changing the framework conditions in each State, by, for instance, making the legislation and institutions more suitable, and providing for regular funding and suitable equipment. As an example, Spain's Ministry of Culture produced its National Plan for the Protection of Underwater Cultural Heritage in 2007 and a strategy to ensure the standardised implementation of this plan by Spain's regions and institutions was produced by the Heritage Council in 2009 (Grupo de Trabajo del Comite de Coordinacion Technica del Consejo del Patrimonio Historico 2009; Ministerio de Cultura 2007). Such efforts are also not always successful. In Montenegro a strategy was created in 2001, with an outline of the steps needed to create an underwater archaeological institution, examples of how it is done in other States, costings for the proposal, and suggested necessary legislative reform (Karović 2001; M1). Its proposals, however, failed to materialise. Without the backing of the State, these initiatives, which may advocate far reaching institutional reforms and the reallocation of significant resources, may prove difficult. Less ambitious strategies could be produced by those wanting to build capacities, which could still generate change whilst working largely within the existing framework conditions. For instance, a national set of guidelines could provide archaeologists without a maritime archaeological background employed in the Soprintendenze in Italy with a basic knowledge of how to approach underwater cultural heritage in their territories, and what standards need to be met (I3; I6). This would begin to standardise research and protection efforts and help maintain institutional knowledge when actors leave their roles.

Research frameworks are a tool used to lay out research priorities in order to inform other archaeologists, those that fund archaeology, and policy makers (examples from the UK include Atkinson and Hale 2012; Ransley and Sturt 2013). A research framework in Croatia could help the Ministry give precedence to projects which meet the priorities agreed upon by the archaeological community, allowing funding to be better targeted and projects to be completed to a fuller extent and higher standards. Any further capacity development efforts in Montenegro should be part of a wide-ranging strategy that also seeks to build the public and political awareness of maritime archaeology.

Creating strategies to develop capacity in maritime archaeology and underwater cultural heritage protection could help produce long term gains, but only if they are tailored to each States' unique amalgam of framework conditions and situative contexts. Analysis of the framework conditions and the development of a suitable strategy should form a key stage in all capacity development efforts. 


\section{Conclusion}

Capacity as a concept is multifaceted. The factors that affect capacity are interrelated and interact with each other. Each State, region or territory that engages in maritime archaeology has its own unique set of circumstances, none of which are static. This makes capacity development an inexact science (Browne 2002: 3). The lessons learnt in the environmental sciences however, could aid such efforts in maritime archaeology. If these lessons are heeded, and the extensive literature available in other subject areas is engaged with, the limited resources available to maritime archaeologists could be used in a manner in which their impact is maximised.

Mono-factorial approaches, such as only training individuals, are unlikely to succeed if they are not part of wider efforts that seek to understand and alter the particular framework conditions in each State. That is not to say that such work that has gone before is not useful, and the tireless efforts of individuals and organisations trying to raise capacity in maritime archaeology should be commended and encouraged. Yet a more holistic approach is possible, and interventions can be cross-cutting, aimed at addressing multiple aspects of the concept of capacity. Some aspects of the theoretical framework of capacity will be more difficult to alter than others, the economic-technological framework conditions for instance will often be beyond the abilities of maritime archaeologists to change, but they can still be taken into account. Creating strategies for capacity development tailored to the individual State through an analysis of the context is an essential step in designing successful capacity development initiatives. These can identify the factors that limit capacity, recognise which ones can be changed, and outline appropriate measures. The development of such strategies could be the quickest and easiest way to incite long term improvements in capacity. Capacity development efforts must at the very least be aware of the structural conditions which limit them.

In the environmental literature the preferred term is now 'capacity development' rather than 'capacity building', due to the focus being on long-term processes rather than single actions or outcomes (Sagar 2000: 383). As a discipline maritime archaeology needs to move to this stage too, not focussing on single initiatives without any thought for context. That can only be done by engaging with a wider theoretical concept of capacity, an honest look at the structural framework conditions of each State, and forming strategic capacity development efforts to alter them.

Acknowledgements This paper has been produced from doctoral research undertaken at the University of Southampton. Fieldwork was funded by the Honor Frost Foundation and the wider doctoral research was funded by the Southampton Marine and Maritime Institute. Fieldwork was approved by the University of Southampton under ethics number 20049. Transcripts of the interviews are on file with the author. Many thanks must be extended to the interview participants in Croatia, Italy and Montenegro, all of whom were very generous with their time, their opinions, and regularly also with coffees and beers. Any errors are entirely the fault of the author. Thanks also to Mladen Pešić for his comments on the current situation in Croatia. Finally, thanks to Lucy Blue for her comments on this article and for her expert advice and tireless support when supervising the Ph.D. from which it was produced.

Funding This study was funded by the Honor Frost Foundation and the Southampton Marine and Maritime Institute.

\section{Compliance with Ethical Standards}

Conflict of interest The authors declare that they have no conflict of interest. 
Open Access This article is distributed under the terms of the Creative Commons Attribution 4.0 International License (http://creativecommons.org/licenses/by/4.0/), which permits unrestricted use, distribution, and reproduction in any medium, provided you give appropriate credit to the original author(s) and the source, provide a link to the Creative Commons license, and indicate if changes were made.

\section{Legislation}

'Agreement between UNESCO and the Government of the Republic of Croatia Regarding the Establishment of the Regional Centre for Underwater Archaeology in Zadar, Croatia as a Category 2 Centre under the Auspices of UNESCO'. Signed 1 August 2008

Constitution of the Italian Republic, as amended, 1947

Decreto 208/2016, Riorganizzazione del Ministero dei beni e delle attivita' culturali e del turismo ai sensi dell'articolo 1, comma 327, della legge 28 dicembre 2015

Decreto Legislativo 42/2004, Cultural Heritage and Landscape Code

Proposta di legge 2302 'Istituzione della Soprintendenza del mare e delle acque interne e organizzazione del settore del patrimonio storico-culturale sommerso nell'ambito del Ministero per i beni e le attività culturali' Presented on 18 March 2009

Proposta di legge 470 'Organizzazione del settore dell'archeologia subacquea nell'ambito del Ministero per $i$ beni e le attività culturali e istituzione dell'Istituto centrale per l'archeologia subacquea' Presented on 21 March 2013

\section{References}

Anderson R (2014) Report on 'international capacity building on safeguarding the underwater cultural heritage' (Kegiatan Bimbingan Teknis Cagar Budaya Bawah Air Tingkat Internasional Tahun 2014) training activities: Makassar, Sulawesi, Indonesia, 21 September-7 October 2014. Western Australian Museum Report No. 311

Atkinson D, Hale A (eds) (2012) From source to sea: scottish archaeological research framework marine and maritime panel report. Society of Antiquaries of Scotland, Edinburgh

Browne S (ed) (2002) Developing capacity through technical cooperation: country experiences. Earthscan Publications Ltd, London

Favis RL, Manders MR, Underwood CJ (2012) Introduction: the development of the regional capacity building programme on underwater cultural heritage. In: Manders MR, Underwood CJ (eds) Training manual for the UNESCO foundation course on the protection and management of underwater cultural heritage in Asia and the Pacific. UNESCO, Bangkok

Firth A (2015) The social and economic benefits of marine and maritime cultural heritage: towards greater accessibility and effective management. Fjordr Limited for Honor Frost Foundation, London

Florea R, Gheorghiu G (2015) Review of the international centre for underwater archaeology: final report. Strategicus Consulting, Bucharest

Grupo de Trabajo del Comite de Coordinacion Technica del Consejo del Patrimonio Historico (2009) Green paper: national plan for the protection of underwater cultural heritage. Ministerio de Cultura, Cartagena

Jänicke M (1997) The political system's capacity for environmental policy. In: Jänicke M, Weidner H (eds) National environmental policies: a comparative study of capacity building. Springer, Berlin, pp 1-24

Karović G (2001) Центар за подводна археолошка истраживања Црне Горе: оснивачки пројекат [Centre for Underwater Archaeological Research of Montenegro: the founding project]. Public Enterprise for Coastal Zone Management of Montenegro, Budva

MacKintosh R (2018) The 2001 UNESCO convention on the protection of the underwater cultural heritage: implementation and effectiveness. PhD Thesis, University of Southampton

Manders M, Underwood CJ (2015) UNESCO field school on underwater cultural heritage 2009-2011, Thailand: capacity building in the Asian and Pacific region. In: Tripathi S (ed) Shipwrecks around the world: revelations of the past. Delta Book World, New Delhi, pp 730-748

Mason J (2002) Qualitative researching, 2nd edn. SAGE Publications, London 
Ministerio de Cultura (2007) Plan Nacional de Proteccion del Patrimonio Arqueologico Subacuatico www. mecd.gob.es/cultura-mecd/eu/areas-cultura/patrimonio/patrimonio-subacuatico/plan-nacional-de-prote ccion.html. Accessed 30 November 2017

OECD (2012) Greening development: enhancing capacity for environmental management and governance. OECD Publishing, Paris

Rossi IR (2012) Underwater cultural heritage and maritime archaeology in Croatia: an overview. Eur J Archaeol 15:285-308

Ransley J, Sturt F (eds) (2013) People and the sea: a maritime archaeological research agenda for England. Council for British Archaeology, New York

Ratzenböck V, Okulski K, Kopf X (2012) Cultural policy landscapes: a guide to eighteen Central and South Eastern European countries. ERSTE Foundation and österreichische kulturdokumentation. internationales archiv für kulturanalysen, Vienna

Sagar AD (2000) Capacity development for the environment: a view for the south, a view for the north. Annu Rev Energy Environ 25:377-439

Sagar AD, VanDeveer SD (2005) Capacity development for the environment: broadening the scope. Glob Environ Polit 5:14-22

Secci M, Stefanile M (2016) Sailing heavy weather: underwater cultural heritage management in Italy. In: Actas Del V Congreso Internacional de Arqueología Subacuática (IKUWA V): Cartagena, 2014. Ministerio de Educación, Cultura y Deporte, Madrid. pp 99-106

Stefanile M (2014) La Soprintendenza del Mare e l'importanza dell'esempio siciliano. Archaeol Maritima Mediterr. Int J Underw Archaeol 11:168-170

Throckmorton P (ed) (1996) The sea remembers: shipwrecks and archaeology, 2nd edn. Chancellor Press, London

Ucelli G (1950) La Navi di Nemi. Libreria dello Stato, Rome

UN Conference on Environment and Development (1992) National mechanisms and international co-operation for capacity-building in developing countries. In: Report of the United Nations conference on the environment and development, A/CONF.151/26, Vol. III. United Nations, New York

UNESCO (2017) UNESCO capacity-building programme on underwater cultural heritage protection. UNESCO. www.unesco.org/new/en/culture/themes/underwater-cultural-heritage/education/capacity-build ing-programme/. Accessed 11 June 2017

United Nations Development Programme (2008) Supporting capacity development: the UNDP approach. United Nations Development Programme Bureau for Development Policy, New York

Yardley J, Pianigiani G (2014) Venice mayor is arrested in corruption charges. New York Times. www. nytimes.com/2014/06/05/world/europe/venice-mayor-is-arrested-on-corruption-charges.html. Accessed 28 January 2019

Publisher's Note Springer Nature remains neutral with regard to jurisdictional claims in published maps and institutional affiliations. 